Author(s):

Submitted to:
Craig Taylor, CST-12

\section{Chuck Wilkerson, CST-1}

RECEIVED

EEC 02990

OSTI
DOE Office of Scientific and Technical Information (OSTI)
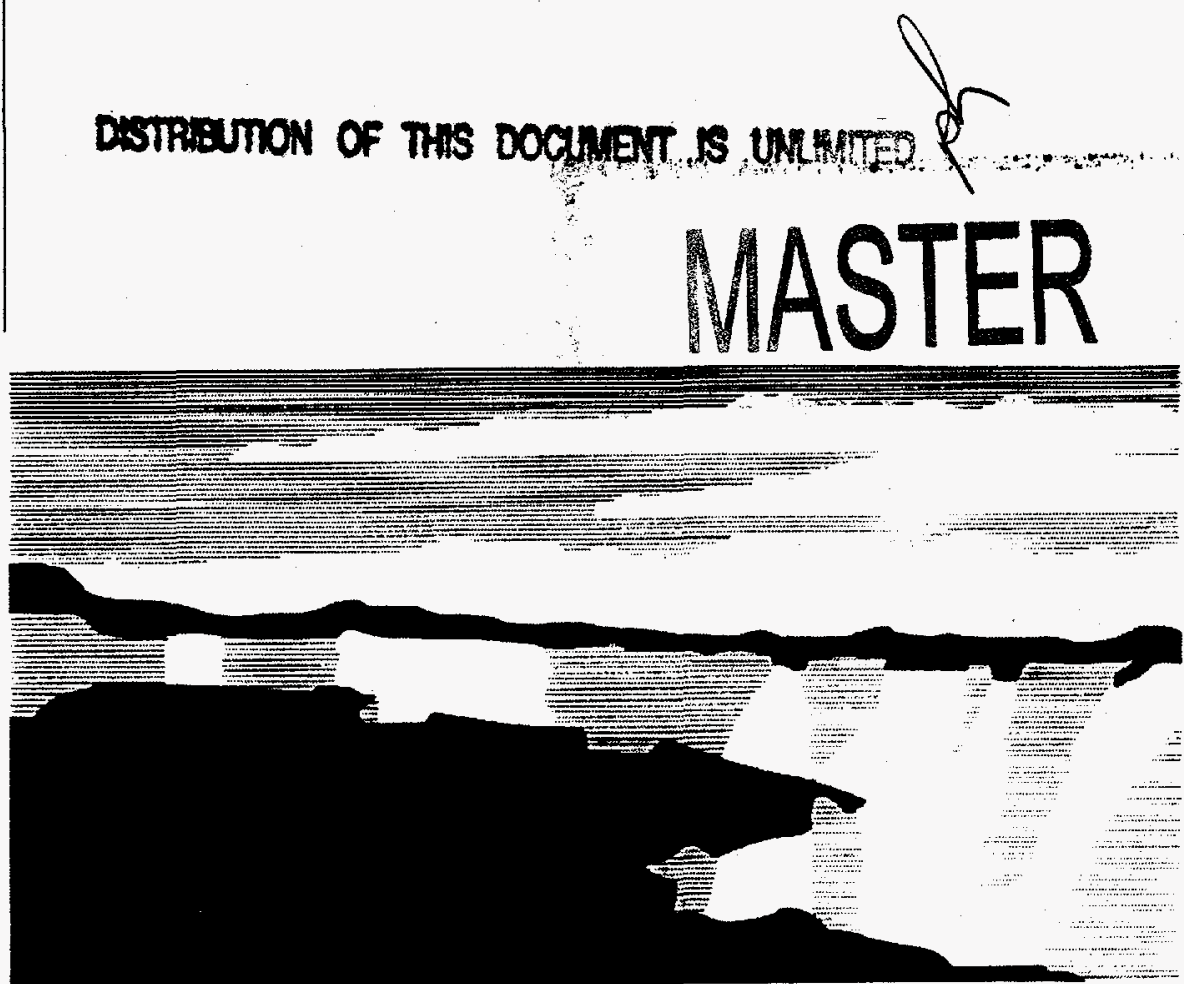

Los Alamos National Laboratory, an affirmative actionvequal opportunity employer, is operated by the University of Calfornia for the U.S. Department of Energy under contract W-7405-ENG-36. By acceptance of this article, the publisher recognizes that the U.S. Government retains a nonexclusive, royaltyfree license to publish or reproduce the published form of this contrbution, or to allow others to do so, tor U.S. Govermment purposes. The Los Alamos National Laboratory requests that the publisher identify this anticle as work performed under the auspices of the U.S. Department of Energy. 


\section{DISCLAIMER}

Portions of this document may be illegible in electronic image products. Images are produced from the best available original document. 


\section{DISCLAIMER}

This report was prepared as an account of work sponsored by an agency of the United States Government. Neither the United States Government nor any agency thereof, nor any of their employees, makes any warranty, express or implied, or assumes any legal liability or responsibility for the accuracy, completeness, or usefulness of any information, apparatus, product, or process disclosed, or represents that its use would not infringe privately owned rights. Reference herein to any specific commercial product, process, or service by trade name, trademark, manufacturer, or otherwise does not necessarily constitute or imply its endorsement, recommendation, or favoring by the United States Government or any agency thereof. The views and opinions of authors expressed herein do not necessarily state or reflect those of the United States Government or any agency thereof. 


\title{
Surface Polymerization Agents
}

\author{
Craig Taylor* and Chuck Wilkerson
}

\begin{abstract}
This is the final report of a one-year, Laboratory-Directed Research and Development (LDRD) project at the Los Alamos National Laboratory (LANL). A joint technical demonstration was proposed between the US Army Missile Command (Redstone Arsenal) and LANL. The objective was to demonstrate that an unmanned vehicle or missile could be used as a platform to deliver a surface polymerization agent in such a manner as to obstruct the filters of an airbreathing mechanism resulting in operational failure.
\end{abstract}

\section{Background and Research Objectives}

Surface polymerization agents (SPAs) are materials that can be used to block the flow of air through particulate filter systems. The primary application of SPA technology is for disabling engines. However, it could be used successfully against any system requiring filtered air, such as command and control centers, computer facilities, underground bunkers, and personal protection devices. In the primary application it would very effectively shut down an air-breathing machine without major harm to the workings. The target may be brought back into service simply by removing and replacing the affected filter. However, this material can cause serious damage to the internal workings of the target if the target is not fitted with a filter system. The overall objective of this project was to demonstrate the use of an unmanned vehicle or missile as a delivery platform for SPAs through a joint technical demonstration with US Army Missile Command (MICOM), Redstone Arsenal. The specific objective was to experiment with the chemistry of the SPA to optimize its performance in the MICOM demonstration. Various degrees of experimental freedom were exercised and agent characteristics observed.

\footnotetext{
*Principal investigator, E-mail: eggus_taylor@lanl.gov
} 


\section{Importance to LANL's Science and Technology Base and National R\&D Needs}

This technology utilizes Laboratory expertise in chemistry and materials and supports Los Alamos core competencies in nuclear and advanced materials as well as earth and environmental systems. The application of this technology to defense needs is both timely and significant.

\section{Scientific Approach and Results to Date}

Variations in the molecular weight of the polymer, the concentrations of the polymer and cross-linking agents, and the stoichiometry of the binary mixture have been investigated. The range of morphologies attainable is very broad, ranging from nearly free-flowing liquid to semi-solid. It was found that, with high molecular weight polymers, a low concentration (2$4 \%$ by weight) of material could produce a very tenacious agent. A potential disadvantage of the high molecular weight SPAs is their limited water solubility, which could complicate field preparation of the solution. It was not uncommon for 120 hours to be needed before a homogeneous fluid was obtained. Lower molecular weight polymers had significantly better solubility properties, but also exhibited lower viscosities.

Originally, it was anticipated that dispersal of the SPA would be through a spray nozzle under the influence of pressurized gas. The interaction of the gas with the agent, particularly on the $\mathrm{pH}$ of the binary mixture, was a point of concern. Experiments to determine the effect of drive-gas composition and concentration were not carried out after discussions with MICOM suggested that the demonstration would utilize an explosive mechanism to disperse the SPA. This issue (use of a pressurized delivery system and the effect of the gas on SPA performance) has still not been addressed.

The viscosity properties of the agent can be tuned, as suggested above, by varying the chemical nature of the system. The optimum mixture for a particular application will be influenced by the means of delivery and the size and nature of the objective.

In addition to laboratory studies, a literature investigation into the potential toxicological effects of the agent was carried out. No evidence indicating serious health concerns was discovered. However, inhalation of the aerosolized agent has not been studied and this is the most likely scenario that would be encountered in the use of SPA technology.

Los Alamos' contribution to the technical demonstration was to have been the SPA material. Our effort was directed towards delivery of an appropriate sample that met MICOM requirements. Due to various difficulties, those specifications are still not final. In addition, the schedule for the technical demonstration is currently uncertain. 